\title{
Myectomy site thrombus formation: An underappreciated source of thromboembolism after septal myectomy
}

\author{
Niranjan Seshadri, MD, ${ }^{a}$ Gian M. Novaro, MD, ${ }^{a}$ Harry Lever, MD, ${ }^{a}$ Richard D. White, MD, ${ }^{b}$ Nicholas Smedira, MD,

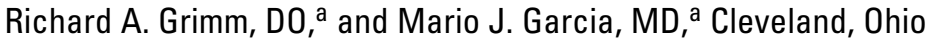

From the Departments of Cardiology, Radiology, ${ }^{\mathrm{b}}$ and Cardiothoracic Surgery, ${ }^{\mathrm{c}}$ The Cleveland Clinic Foundation, Cleveland, Ohio.

Received for publication Aug 15, 2001; accepted for publication Sept 17, 2001.

Address for reprints: Mario J. Garcia, MD, Department of Cardiology, Section of Cardiovascular Imaging, The Cleveland Clinic Foundation/Desk F-15, 9500 Euclid Ave, Cleveland, OH 44195 (E-mail: garciam@ccf.org).

J Thorac Cardiovasc Surg 2002;123:562-4

Copyright (๑) 2002 by The American Association for Thoracic Surgery

0022-5223/2002 $\$ 35.00+0 \quad \mathbf{1 2 / 5 4 / 1 2 0 7 1 9}$

doi:10.1067/mtc.2002.120719

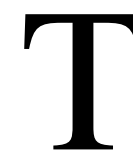

hromboembolic complications of hypertrophic cardiomyopathy (HCM) usually occur in the setting of atrial fibrillation, left atrial, or left ventricular abnormalities. ${ }^{1-3}$ Thrombus formation in the left ventricular outflow tract (LVOT), however, whether spontaneous or in the postoperative setting, is thought to be exceedingly uncommon, particularly in the absence of the aforementioned risk factors. Our report describes the development of LVOT thrombus in a patient with obstructive HCM after septal myectomy in association with postoperative embolic neurologic events.

\section{Clinical Summary}

A 58-year-old woman was referred to our institution for elective surgical myectomy for symptomatic obstructive HCM. Several months before the operation, she reported increasing dyspnea on exertion refractory to maximal medical therapy. Her history was significant for idiopathic thrombocytopenic purpura, hypertension, hypothyroidism, and osteoarthritis. She had also undergone several abdominal and gynecologic procedures with uncomplicated postoperative courses. She denied a history of syncopal or presyncopal episodes, as well as any history of atrial fibrillation, strokes, or transient ischemic attacks. Family history was significant for HCM and sudden cardiac death in several family members.

A cardiac catheterization performed before the operation revealed normal coronary arteries. An exercise stress echocardiogram showed normal resting left ventricular size and systolic function with an estimated ejection fraction of $60 \%$, systolic anterior motion of the mitral valve, and $3+$ mitral regurgitation. There were no regional left ventricular wall motion abnormalities, and the left atrial diameter was $3.9 \mathrm{~cm}$. Peak dynamic gradient across the LVOT was $88 \mathrm{~mm} \mathrm{Hg}$ after provocation with exercise.

The patient underwent successful septal myectomy with an uncomplicated intraoperative course. The myectomy specimen showed myocyte hypertrophy and disarray consistent with HCM. An intraoperative transesophageal echocardiogram revealed no resting or provokable gradient across the LVOT, 1+ mitral regurgitation, and no systolic anterior motion of the mitral valve. Atrial fibrillation developed on the third postoperative day but within 24 hours was pharmacologically converted to normal sinus rhythm. No further episodes of atrial fibrillation occurred. On the seventh postoperative day, the patient had several discrete transient ischemic attacks manifesting as visual field disturbances. Magnetic resonance imaging showed small areas of acute ischemia in the right middle frontal gyrus and right occipital pole, raising the suspicion of an embolic origin. Transesophageal echocardiography subsequently showed 2 nonmobile echo densities in the LVOT at the myectomy site suggestive of thrombi (Figure 1). The left-sided heart valves and ascending aorta appeared normal, and no thrombus was detected in the left atrium or atrial appendage. The patient was thus started on intravenous unfractionated heparin because of her neurologic events and echocardiographic findings. To further define the cardiac masses, a magnetic resonance imaging study was performed identifying 2 pedunculated intracavitary masses in the LVOT consistent with thrombi, the largest of which was $9 \times 6 \mathrm{~mm}$ (Figure 2). Her clinical course stabilized without further evidence of embolic events. Two days later, she became dyspneic and hypotensive. A repeated trans- 


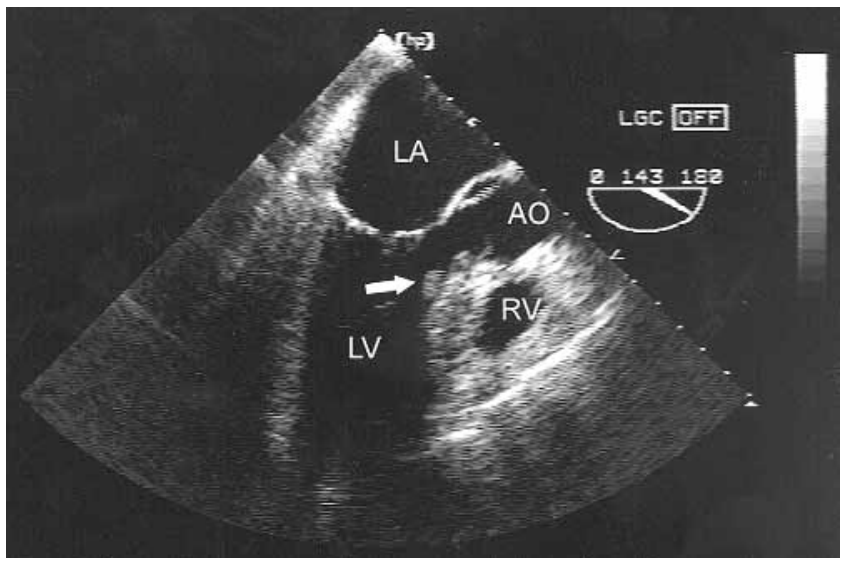

Figure 1. Transesophageal echocardiography in the $\sim 140^{\circ}$ long-axis view showing an echo density at the myectomy site suggestive of thrombus (arrow). $A O$, Aorta; $L A$, left atrium; $L V$, left ventricle; $R V$, right ventricle.
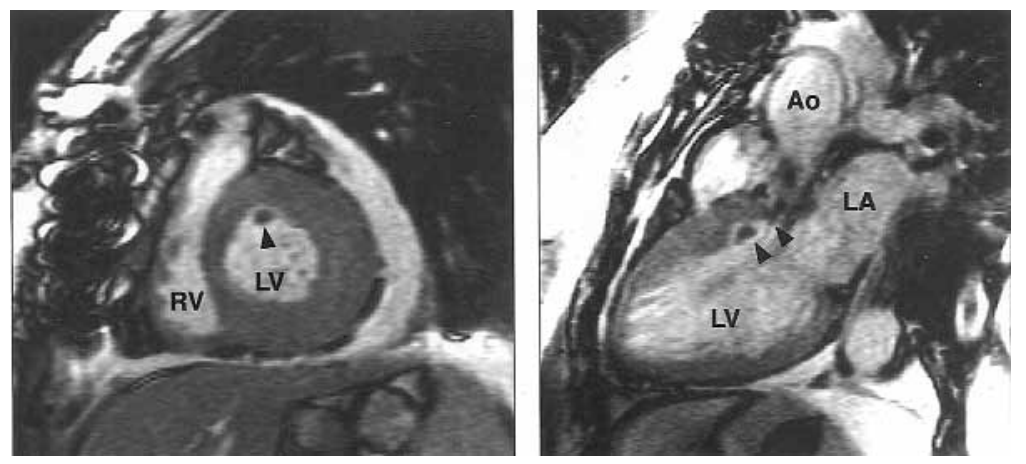

Figure 2. Small polypoid intracavitary lesions (arrowheads) attached to the endocardium of the outflow tract of the left ventricle are seen on basal short-axis and 3-chamber long-axis images from dynamic "bright blood" (cine) magnetic resonance image-loops. Ao, Aorta; $L A$, left atrium; $L V$, left ventricle; $R V$, right ventricle.

esophageal echocardiogram showed no change in the intracavitary masses; however, a large posterior loculated pericardial effusion with associated tamponade was noted. The patient was taken to the operating room where she underwent evacuation of the pericardial effusion and removal of 4 masses along the LVOT, all attached to the myectomy site. Pathologic examination was consistent with thrombi. Oral anticoagulation therapy was initiated shortly after reoperation and, on the 18th postoperative day, she was discharged from the hospital in stable condition.

\section{Discussion}

Obstructive HCM is characterized by asymmetric hypertrophy of the left ventricle with dynamic variable obstruction along the outflow tract. The cardiomyopathy has a prevalence estimated at $0.2 \%$ of the general population and is associated with devastating manifestations such as sudden cardiac death and thromboembolic events. ${ }^{2,4-6}$ The incidence of systemic thromboembolism in patients with $\mathrm{HCM}$ is estimated at $3 \%$ to $7 \%$ per year. ${ }^{2,3}$ Thromboembolic events are usually in the setting of atrial fibrilla- tion, which is present in about $15 \%$ of such patients. ${ }^{4-6}$ Other factors contributing to the increased risk of thromboembolism include left ventricular systolic dysfunction and left atrial dilatation, particularly when coupled with atrial fibrillation.

Because the occurrence of our reported finding in large published surgical series is nearly nonexistent, this report suggests that our patient may have had an underlying hypercoagulable state. Although a complete thrombophilia evaluation was not performed, the patient's history of idiopathic thrombocytopenic purpura may have been associated with a relative propensity for thrombus formation. Arterial thromboses have been known to occur in the setting of this condition, although the mechanism is poorly understood. ${ }^{7}$ Additionally, evidence exists of activation of the coagulation system in patients with HCM as shown in a study by Yamamoto and associates. ${ }^{8}$ These investigators documented increased levels of two specific markers of activation of the coagulation system in patients with HCM. Furthermore, these markers significantly correlated with left atrial size; our patient's left atrium, however, was only mildly dilated. 
In our patient, none of the traditional predisposing factors for thromboembolism were present. Nevertheless, the thrombus formation occurred in an unusual location, the myectomy site in the LVOT, a location that is not mentioned in the reported literature. The LVOT is an area of high-velocity, turbulent flow, which should protect against thrombus formation. In large series of patients undergoing surgical myectomy, thromboembolic events in the postoperative period are uncommon, with the prevalence of stroke being $0 \%$ to $1 \% .^{9-11}$ Brunner-La Schonbeck and colleagues, ${ }^{11}$ in their series of 110 patients undergoing surgical myectomy, reported the maintenance use of warfarin in the postoperative setting, up to 3 months, as prophylaxis against thromboemboli stemming from the myectomy site. Other series report the postoperative use of warfarin only in those with chronic atrial fibrillation. ${ }^{9}$ The practice of routine postoperative anticoagulation after surgical myectomy is controversial, with scarce data on the true incidence of subclinical thrombus formation at the myectomy site. With the relatively low early and late postoperative stroke rates in postmyectomy patients, it is likely that the actual occurrence is low. Although specific guidelines do not exist regarding postoperative anticoagulation regimens, our current practice has included low-dose daily aspirin in the early and late postoperative period, unless a history of atrial fibrillation or prior stroke coexists.

In conclusion, our report is the first, to our knowledge, to clearly document postoperative thrombus formation at the myectomy site in a patient with HCM. This potential source of thromboemboli should be taken into account in the evaluation of postoperative stroke in patients undergoing surgical septal myectomy. Until further data exist, routine postoperative use of an antiplatelet agent after surgical septal myectomy appears warranted.

\section{References}

1. Henry WL, Morganroth J, Pearlman AS, Clark CE, Redwood DR, Itscoitz SB, et al. Relation between echocardiographically determined left atrial size and atrial fibrillation. Circulation. 1976;53:273-9.

2. Furlan AJ, Craciun AR, Raju NR, Hart N. Cerebrovascular complications associated with idiopathic hypertrophic subaortic stenosis. Stroke. 1984;15:282-4.

3. Shigematsu Y, Hamada M, Mukai M, Matsuoka H, Sumimoto T, Hiwada K. Mechanism of atrial fibrillation and increased incidence of thromboembolism in patients with hypertrophic cardiomyopathy. Jpn Circ J. 1995;59:329-36.

4. Savage DD, Seides SF, Maron BJ, Myers DJ, Epstein SE. Prevalence of arrhythmias during 24-hour electrocardiographic monitoring and exercise testing in patients with obstructive and nonobstructive hypertrophic cardiomyopathy. Circulation. 1979;59:866-75.

5. McKenna WJ, England D, Doi YL, Deanfield JE, Oakley C, Goodwin JF. Arrhythmia in hypertrophic cardiomyopathy. I: Influence on prognosis. Br Heart J. 1981;46:168-72.

6. Koga Y, Itaya K, Toshima H. Prognosis in hypertrophic cardiomyopathy. Am Heart J. 1984;108:351-9.

7. Jackson SP, Jane SM, Mitchell CA, Fernando Cortizo W, Hau L, Pfueller SL, et al. Arterial thrombosis associated with immune thrombocytopenia: presence of a platelet aggregating $\mathrm{IgG}$ synergistic with thrombin and adrenalin. Thromb Haemost. 1989;62:846-9.

8. Yamamoto K, Ikeda U, Furuhashi K, Irokawa M, Nakayama T, Shimada K. The coagulation system is activated in idiopathic cardiomyopathy. J Am Coll Cardiol. 1995;25:1634-40.

9. Cohn LH, Trehan H, Collins JJ. Long-term follow-up of patients undergoing myotomy/myectomy for obstructive hypertrophic cardiomyopathy. Am J Cardiol. 1992;70:657-60.

10. Heric B, Lytle BW, Miller DP, Rosenkranz ER, Lever HM, Cosgrove DM. Surgical management of hypertrophic obstructive cardiomyopathy: early and late results. J Thorac Cardiovasc Surg. 1995;110:195206; discussion 206-8.

11. Brunner-La Schonbeck MH, Rocca HP, Vogt PR, Lachat ML, Jenni R, Hess OM, et al. Long-term follow-up in hypertrophic obstructive cardiomyopathy after septal myectomy. Ann Thorac Surg. 1998;65:1207-14. 